\title{
IMPACT OF FIRE-THROUGH AND MISFIRE IN RECTIFIER VALVES ON A TURBINE GENERATOR NEIGHBORING TO A HVDC INVERTER STATION
}

Ming-Te Liang

Department of Civil Engineering, China Institute of Technology, Taipei, Taiwan, R.O.C., mtliang@cc.chit.edu.tw

Follow this and additional works at: https://jmstt.ntou.edu.tw/journal

Part of the Civil and Environmental Engineering Commons

\section{Recommended Citation}

Liang, Ming-Te (2008) "IMPACT OF FIRE-THROUGH AND MISFIRE IN RECTIFIER VALVES ON A TURBINE GENERATOR NEIGHBORING TO A HVDC INVERTER STATION," Journal of Marine Science and Technology. Vol. 16: Iss. 4, Article 1. DOI: $10.51400 / 2709-6998.2003$

Available at: https://jmstt.ntou.edu.tw/journal/vol16/iss4/1

This Research Article is brought to you for free and open access by Journal of Marine Science and Technology. It has been accepted for inclusion in Journal of Marine Science and Technology by an authorized editor of Journal of Marine Science and Technology. 
IMPACT OF FIRE-THROUGH AND MISFIRE IN RECTIFIER VALVES ON A TURBINE GENERATOR NEIGHBORING TO A HVDC INVERTER STATION

Acknowledgements

The writer would like to thank National Science Council of the Republic of China for Financial support of this study under Contract No. NSC 93-2211-E-157-006. 


\title{
IMPACT OF FIRE-THROUGH AND MISFIRE IN RECTIFIER VALVES ON A TURBINE GENERATOR NEIGHBORING TO A HVDC INVERTER STATION
}

\author{
Chi-Hshiung Lin*
}

Key words: HVDC Link, turbine generator, fire-through, misfire.

\begin{abstract}
In general, a fault that is far away from a generator would not cause serious impact to the generator. However, it is not the case for a generator in a HVDC system. For a HVDC link, the rectifier end is usually in several hundreds of kilometer away from the inverter end. It is found in this paper that both the fire-through and misfire faults happened in the rectifier valves may still make a serious impact on the inverter side generators. However, the impacting phenomena are different. A sustained fire-through fault happened in rectifier valves may induce the torsional interaction between the HVDC link and a nearby turbine generator in inverter end. This provides the chance for an electromechanical resonance to build up. A misfire fault happened in a rectifier valve could induce a non-negligible transient power disturbance on a turbine generator neighboring to the HVDC inverter station. The disturbing frequencies will be non-characteristic for the generator. On occasion of any of the torsional modes of the turbine generator are invaded, the torsional torque amplification effect would be significant.
\end{abstract}

\section{INTRODUCTION}

Torsional vibrations on a large-scale steam turbine generator have been extensively discussed in many research works. The studies were primarily focused on the fatigue damages on turbine shafts causing by network fault and switching [3], and the measurements of torsional vibrations [6]. Recently, it attracted attentions about augmenting system damping by utilizing power electronic equipments to modulate the effective and/or reactive power [18].

On the other hand, the torsional interaction between a turbine generator and a power system was also noticed [19, 7]. Espe-

Paper submitted 04/18/07; accepted 06/04/07.Author for correspondence: Chi-Hshiung Lin

(e-mail: lin_chi_hshiung@hotmail.com)

*Department of Electrical Engineering, Kao Yuan University, Kaohsiung County, Taiwan, R.O.C. cially for the torsional interaction in a HVDC system [17], many researchers have devoted to this subject. For examples, a lot of studies have been done in depth on some practically live operation HVDC systems in Europe [8-11]. Those studies are mainly on an operation condition of normal and steady state. For the behaviors corresponding to a faulty situation for a HVDC system, the impact caused by the HVDC line fault [21, 4], the converter station fault [5] and the commutation failure fault [12] have been investigated.

For the converter station fault, however, the study didn't include the inverter unit. Since its scope confined to the rectifier side alone, the effect of interaction between converters has not been considered yet. Thus further studies, as in this paper, are necessary.

In this paper, the interaction between rectifier and inverter is focused. By using the modulation theorem and dynamic simulation, it has been analyzed the phenomena for a fire-through fault and for a misfire fault happened in the rectifier valves to impact an inverter side turbine generator.

\section{SYSTEM STUDIED}

\section{System Descriptions}

The system studied is an asynchronous HVDC system as shown in Fig. 1 [1]. A 1,000MW (500kV, 2kA) dc transmission line is used to transmit power from a $10,000 \mathrm{MVA}(345 \mathrm{kV}, 50 \mathrm{~Hz})$ network to a $5,000 \mathrm{MVA}(500 \mathrm{kV}, 60 \mathrm{~Hz})$ network. The converter configuration is typical, including a 12-pulse rectifier and a 12-pulse inverter. The dc transmission line is $300 \mathrm{~km}$, with a $0.5 \mathrm{H}$ of smoothing reactor on each side. The reactive power required by the converters is provided by a set of filters (capacitor bank plus $11^{\text {th }}, 13^{\text {th }}$ and high-pass filters, total 600MVARs on each side). In addition to that a 950MW turbine generator unit is especially added to the network of $60 \mathrm{~Hz}$ side in order for studies. The generator is a 4-poles/1800rpm machine with a voltage rating of $23.75 \mathrm{kV}$, which is driven by a steam turbine unit and supplies power to the converter bus via a step-up transformer (with the power rating of 1057MVA) and two parallel transmission lines. An IEEE TYPE-1 AVR regulates the generator terminal voltage. 


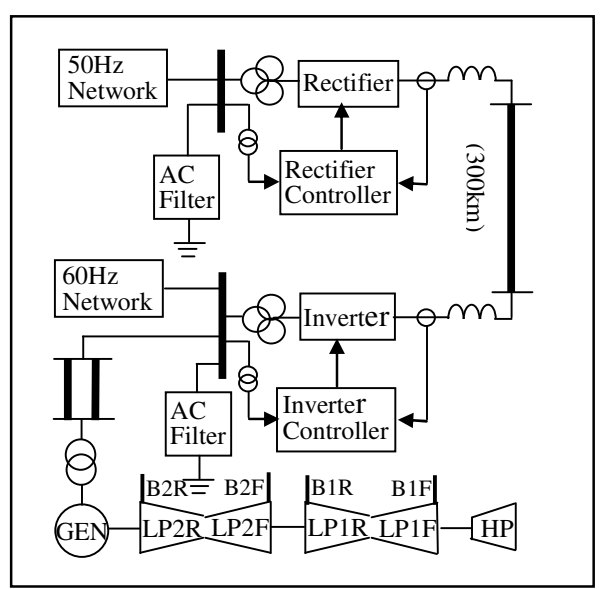

Fig. 1. System studied.

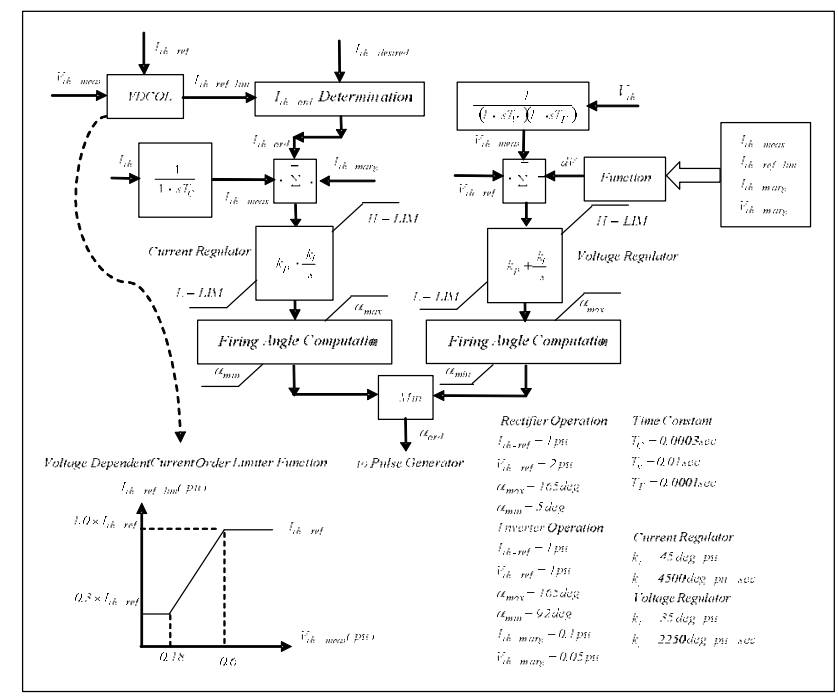

Fig. 3. Converter control model.

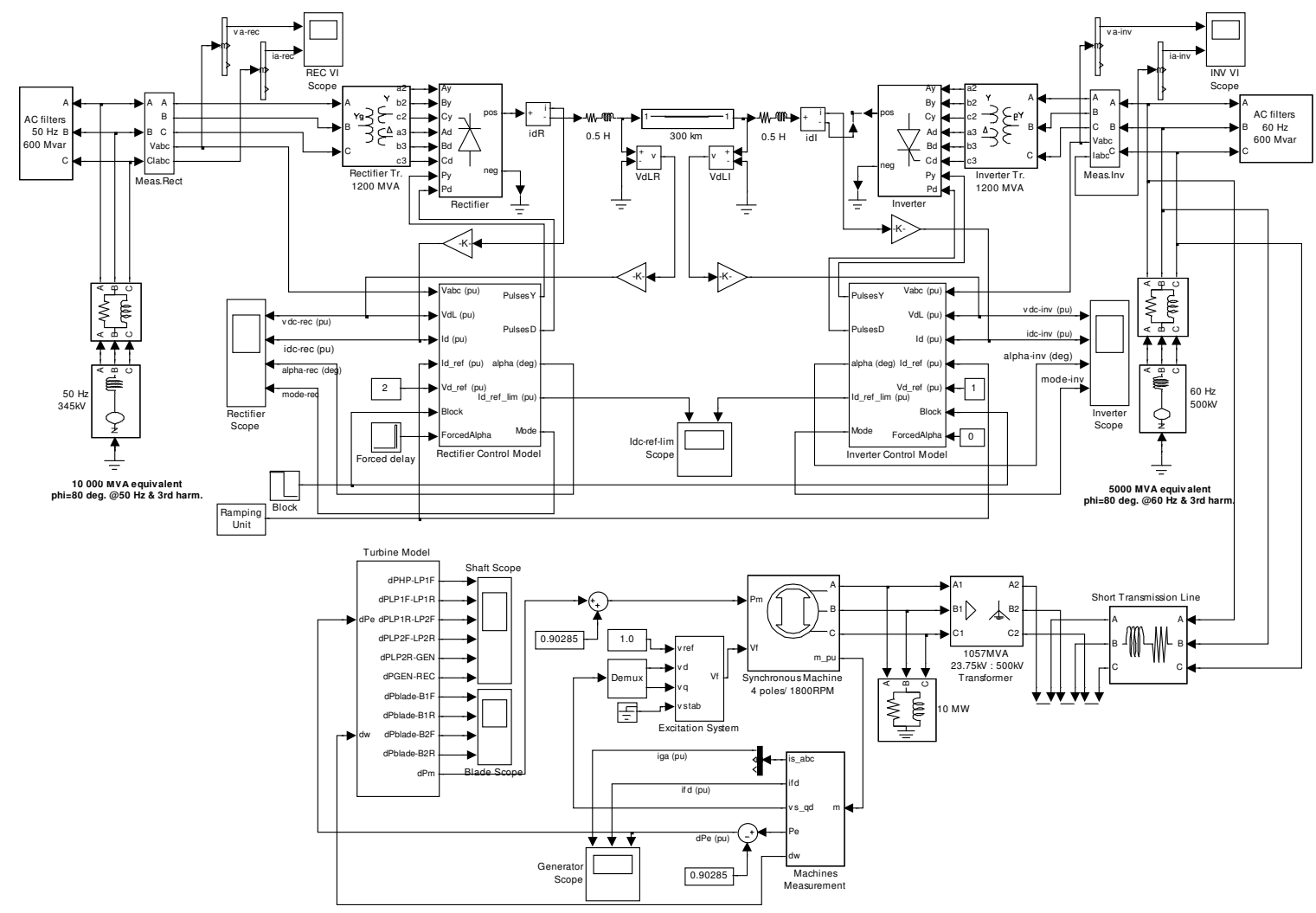

Fig. 2. HVDC system in Matlab/Simulink-power System Blocksets.

\section{System Modeling}

In order for the steady state and transient simulations, a graphic program as shown in Fig. 2 is implemented by using the packaged models of Matlab/Simulink- Power System Blocksets. We don't give unnecessary details of any packaged models but particularly emphasize the HVDC link model and the turbine-generator-exciter-blade model.

\subsection{HVDC Link Model}

It is necessary to model the HVDC link to an extent of sufficiently accurate for transient simulation. The dc transmission line is modeled as a $\pi$ circuit model for considering the capacitive effects. The rectifier and inverter units are composed of thyristors, and an individual thyristor is modeled as a switch in series with a resistor, inductor and voltage drop. The switch will be turn on/turn off (according to the preset switching charac- 


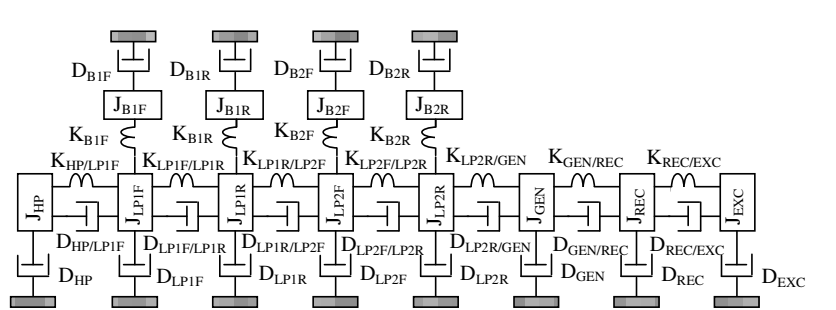

Fig. 4. Mass-damping-spring model of the turbine-generator-exciter-blade structure.

teristics) depending on the firing pulse and thyristor voltage/current. The switching dynamics of a converter (e.g. the commutation failure) could be accurately represented by using such a model.

Detailed converter control model, as shown in Fig. 3, is used. The controller has a voltage and a current regulator operating in parallel. Both the rectifier and the inverter have the same control scheme. Four control modes are available for the converter: 1current control; 2- voltage control; 3- alpha minimum limitation; 4- alpha maximum limitation. For the rectifier, master control is the current control mode. As to the inverter, it is the voltage control mode.

For the master control of a rectifier, the current order is first determined, with constrains being imposed to keep the current within maximum and minimum limits. That is

$$
I_{d c-\text { ord }}=I_{d c-\text { desired }} \text { subject to } 0.3 \times I_{d c-r e f} \leq I_{d c-o r d} \leq I_{d c-r e f-\lim }
$$

The maximum current $\left(I_{d c-r e f-\lim }\right)$ is determined by the Voltage Dependent Current Order Limiter (VDCOL) that is implemented for helping to recover from faults. The PI type of current regulator accounts for the constant current control. The low limit $(L-L I M)$ is set at zero and the high limit $(H-L I M)$ is set according to the following.

$$
\begin{aligned}
& H-L I M=E_{c}\left(\cos \gamma+\cos \alpha_{\min }\right)-2 R_{c} I_{d c} \\
& E_{c}: \text { commutation voltage } \\
& \gamma: \text { inverter extinction angle } \\
& R_{c}: \text { equivalent commutation resistance }
\end{aligned}
$$

The firing angle computation is the heart of control. If the current regulator doesn't hit any limits, the firing angle $(\alpha)$ will be governed by the following equation [2]. The rectifier is thus operating in current control mode.

$$
\begin{aligned}
& \cos \alpha=\frac{V_{C R}+2 R_{c} I_{d c}}{E_{c}}-\cos \gamma \\
& V_{C R}: \text { current regulator output }
\end{aligned}
$$

In case it hits the high limit (i.e. $V_{C R}=H-L I M$ ), the firing angle will be found to be $\alpha_{\min }$. If it hits the low limit (i.e. $\left.V_{C R}=0\right)$, the firing angle will be larger than the one computed

\begin{tabular}{|c|c|c|c|c|}
\hline Rotor & $\begin{array}{l}\text { Torque } \\
\text { Distribu- } \\
\text { tion }(\%) \\
\end{array}$ & $\begin{array}{c}\text { Inertia } \\
\text { Constant } \\
\text { (MW-s/MVA) }\end{array}$ & $\begin{array}{c}\text { Damping } \\
\text { Coefficient } \\
\text { (MW-s/MVA-rad) }\end{array}$ & $\begin{array}{c}\text { Stiffness } \\
\text { Coefficient } \\
\text { (MW/MVA-rad) } \\
\end{array}$ \\
\hline HP & 31 & 0.1787 & 0.00180 & - \\
\hline- & - & - & - & 144.15 \\
\hline LP1F & 14.45 & 0.8510 & 0.00023 & - \\
\hline - & - & - & - & 1595.0 \\
\hline $\begin{array}{c}\text { LP1 } \\
\text { R }\end{array}$ & 14.45 & 0.8432 & 0.00021 & - \\
\hline- & - & - & - & 206.00 \\
\hline LP2F & 14.45 & 0.8545 & 0.00021 & - \\
\hline - & - & - & - & 1584.9 \\
\hline $\begin{array}{c}\mathrm{LP} 2 \\
\mathrm{R}\end{array}$ & 14.45 & 0.8679 & 0.00021 & - \\
\hline - & - & - & - & 325.28 \\
\hline GEN & - & 1.1616 & 0.00012 & - \\
\hline- & - & - & - & 117.16 \\
\hline REC & - & 0.00334 & 0.00000 & - \\
\hline - & - & - & - & 1.61 \\
\hline EXC & - & 0.00236 & 0.00000 & - \\
\hline $\mathrm{B} 1 \mathrm{~F}$ & 2.8 & 0.0344 & 0.00017 & 36.2 \\
\hline $\mathrm{B} 1 \mathrm{R}$ & 2.8 & 0.0344 & 0.00017 & 36.2 \\
\hline $\mathrm{B} 2 \mathrm{~F}$ & 2.8 & 0.0344 & 0.00017 & 36.2 \\
\hline B2R & 2.8 & 0.0344 & 0.00017 & 36.2 \\
\hline
\end{tabular}
by the voltage regulator. Thus, the control mode will be changed to voltage control mode.

For the master control of an inverter, the action is reversed. In normal, the inverter operates in voltage control mode. It will switch to the current control mode when the rectifier regulator
Table 1. Parameters of the mass-damping-spring model.

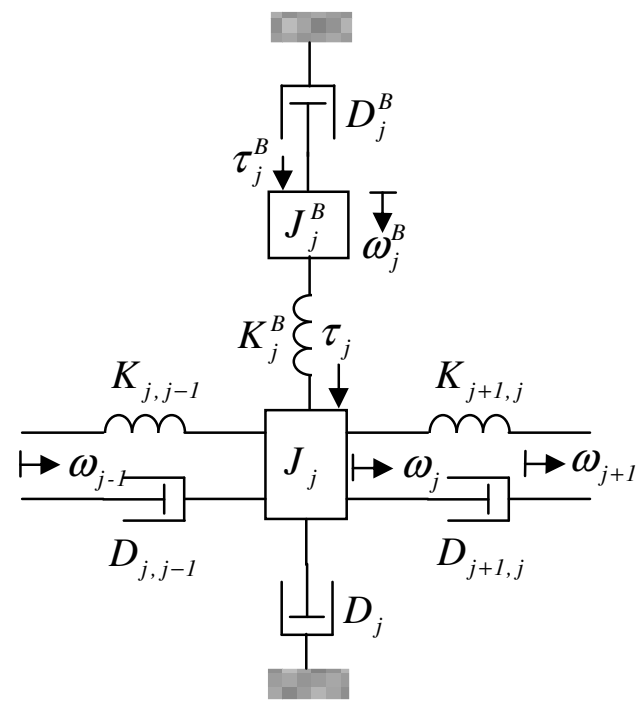

Fig. 5. Rotor-j section of the mass-damping-spring model.

hits $\alpha_{\min }$ and unable to maintain the desired dc current.

\subsection{Turbine-Generator-Exciter-Blade Model}

The steam turbine unit studied, including a high-pressure stage (HP) and two low-pressure stage (LP1, LP2) steam turbines, is a close-coupled and cross-compound reheat unit that operates at a rotational speed of $1800 \mathrm{rpm}$. Each low-pressure turbine has $\mathrm{F}$ and $\mathrm{R}$ spindles, including eleven rows of blades with a twisting structure and a serrated type of root. The first nine rows of blades sheath the disc with shrouds, whereas the last two rows of blades are in a freestanding structure.

It is very difficult to characterize such a complex turbine-generator-exciter-blade structure, yet it has been 


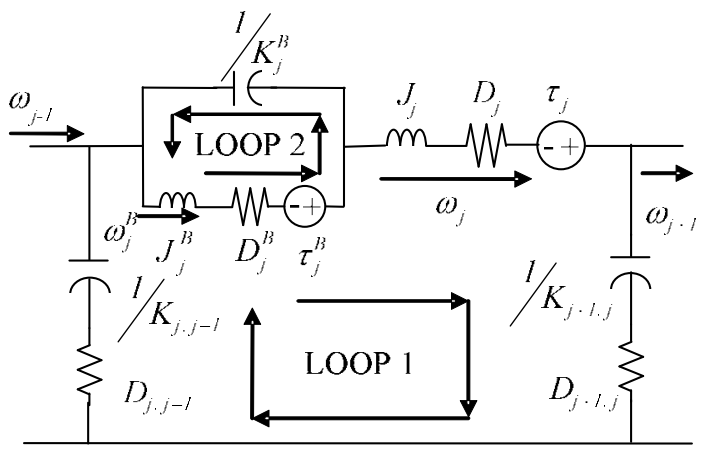

Fig. 6. Equivalent circuit of the rotor-j section.

commonly accepted to use the lumped mass-damping-spring model for the studies on the sub-synchronous resonance (SSR) and torsional vibrations. The model adopted here is shown in Fig. 4, with parameters listed in Table 1. One could refer to [13] or [14] for details of how the model and its parameters were derived.

According to the lumped mass-damping-spring model, dynamic equations of motion can be derived. Here, we use a very particular approach, electromechanical analogy [15], to derive them. For an individual section (e.g. Rotor-j section) as shown in Fig. 5, it can be transformed into an equivalent circuit as in Fig. 6. By the loop analyses, one could find easily the state space equations as the followings.

LOOP 1 equations:

$\frac{d}{d t} \phi_{j}=\omega_{j}$

$\frac{d}{d t} \omega_{j}=\left\{\tau_{j}-\left(D_{j}+D_{j, j-1}+D_{j+1, j}\right) \omega_{j}+D_{j, j-1} * \omega_{j-1}+D_{j+1, j} * \omega_{j+1}-\right.$

$\left.\left(K_{j, j-1}+K_{j+1, j}+K_{j}^{B}\right) \phi_{j}+K_{j, j-1} * \phi_{j-1}+K_{j+1, j} * \phi_{j+1}+K_{j}^{B} * \phi_{j}^{B}\right\} / J_{j}$

LOOP 2 equations:

$\frac{d}{d t} \phi_{j}^{B}=\omega_{j}^{B}$

$\frac{d}{d t} \omega_{j}^{B}=\left(\tau_{j}^{B}+K_{j}^{B} * \phi_{j}-K_{j}^{B} * \phi_{j}^{B}-D_{j}^{B} * \omega_{j}^{B}\right) / J_{j}^{B}$

where $J, K, D$ represent respectively the inertia, stiffness and damping of rotor or of shaft. The $\phi$ and $\omega$ are angular displacement and angular velocity respectively. For turbine rotors, $\tau$ is the torque delivered by the turbine. The torque is determined by the opening of the main control valves (CVs) and reheater/intercepter valves (IVs) that is dependent on turbine governor action. For the generator rotor, $\tau$ is the electromagnetic torque delivered to power system. As to the ones with superscript " $B$ ", they are the blade variables or parameters. By rewriting the torque equations to the power equations and further transforming the equations into the Matlab/Simulink model, the turbine-generator-exciter-blade model can thus be incorporate with the electric power system.

By making an eigen-analysis on the tur-
Table 2. Eigen-values of the mass-damping-spring model.

\begin{tabular}{cccc}
\hline Mode No. & Real & Imaginary & Frequency $(\mathrm{Hz})$ \\
\hline 1 & -1.9562 & 1806.7689 & 287.70 \\
2 & -0.0338 & 627.4918 & 99.92 \\
3 & -0.0290 & 613.0765 & 97.62 \\
$*$ & -0.0557 & 0.0 & $*$ \\
4 & -0.0485 & 104.7038 & 16.67 \\
5 & -0.0328 & 214.0948 & 34.09 \\
6 & -1.3538 & 252.4016 & 40.19 \\
7 & -0.4143 & 285.4803 & 45.46 \\
8 & -0.0706 & 325.8566 & 51.89 \\
9 & -0.0586 & 323.2024 & 51.47 \\
10 & -0.0552 & 312.7360 & 49.79 \\
11 & -0.0569 & 312.8971 & 49.82 \\
\hline *. It is not a vibration mode due to the imaginary part being
\end{tabular}

*: It is not a vibration mode due to the imaginary part being equivalent to zero.

Table 3. Frequencies of the harmonics induced for the fire-through faults.

\begin{tabular}{|c|l|c|}
\hline Case & Faulty Valve No. & Harmonic Frequency \\
\hline $\mathrm{a}$ & 1 & $k f_{R}$ \\
\hline $\mathrm{b}$ & 1,4 & $2 k f_{R}$ \\
\hline $\mathrm{c}$ & $1,3,5$ & $3 k f_{R}$ \\
\hline $\mathrm{d}$ & 1,2 ', 4,5 ' & $4 k f_{R}$ \\
\hline $\mathrm{e}$ & $1,2,3,4,5,6$ & $6 k f_{R}$ \\
\hline Note: " $f_{R}$ " is the nominal frequency of rectifier side, \\
and $k=1,2,3, \ldots$, etc.
\end{tabular}

bine-generator-exciter-blade model, the natural torsional modes can be obtained as in Table 2. Eleven modes are present, of which the former seven belong to the shaft modes and the latter four to the blade modes [13]. Particularly noteworthy is the blade modes, of which the frequencies are close to $50 \mathrm{~Hz}$ (i.e. the system frequency of the sending end network). We will find later it will be harmful to the blade health, though the frequency limitations on natural modes for a $60 \mathrm{~Hz}$ machine are not violated.

\section{ANALYSIS OF A FIRE-THROUGH FAULT HAPPENED IN RECTIFIER VALVES}

A standard 12-pulse HVDC rectifier unit comprises two 6-pulse bridges with Y-Y and Y- $\Delta$ connected transformers respectively. Suppose the valves of the two bridges are numbered 1 to 6 and 1 ' to 6', respectively. In normal operation, the valves will conduct in sequence of 1-1'-2-2'-3-3'-4-4'-5-5'-6-6' in a cycle and repetition.

However, the normal conduction sequence will be disturbed if some of the valves are subjected to a fire-through fault. The fire-through is the conduction of a valve with a correct polarity for commutation before its programmed instant of conduction [5]. For such a fault, the firing angle of the faulty valve is reduced from its normal value to a smaller value or zero. Usually, the resulting disturbance is too small to be detected, thus the 
fault may be sustained for a long time. Therefore, the resulting impact will be in a manner of steady state excitation, which can be analyzed by using the modulation theorem.

\section{Modulation in Rectifier}

Since the disturbance caused by a fire-through fault in the rectifier valves is small, not any of commutation failure would occur. So the faulty valves will disturb the conduction process periodically. This leads to form a modulation action during the rectification, and harmonics are thus induced on the dc line. If it is supposed the firing angle of faulty valves reduces to zero (i.e. the faulty valves act as diodes), Table 3 lists the frequencies of harmonics induced on the dc line for some of the faulty cases. As an illustration, if a fire-through fault occurs in the valves 1 and 4 (or the valves 1, 1', 4 and 4') just as indicated in the case $\mathrm{b}$, one can see that it will strike equally twice a cycle, and reappear in every cycle if the fault is sustained. As a result, the $2^{\text {nd }}$ terms of current harmonics will be induced on the dc line. For other cases, supposing $f_{R}$ to be the nominal frequency of rectifier side, the current harmonics with frequencies of $k f_{R}, 2 k f_{R}, 3 k f_{R}$, $4 k f_{R}$ and $6 k f_{R}$ may be induced depending on the configuration of faulty valves. Since the well-known harmonics, primarily including the 12-th terms of harmonics arising from converters and harmonics attributing to impedances of AC and DC transmission lines in conjunction with filters on both sides, are not in the scope of our studies, they might be neglected. So the dc line current can be expressed as the following for a fire-through fault happened in the rectifier valves [20].

$$
i_{d c}=I_{d c}+\sum_{k=1}^{\infty} M_{k} \sin \left(2 \pi k\left(N f_{R}\right) t+\varphi_{k}\right)
$$

where $N$ equals to $1,2,3,4$ or 6 , depending on the configuration of faulty valves. However, one should note that the limitation of $N k<12$ is required practically because the harmonics of orders of twelve and above will be filtered out by a dc filter. $M_{k}$ is the amplitude of the harmonic current, which is dependent on the severity degree of a fault.

\section{Modulation in Inverter}

When the dc line current flows through the inverter unit to the inverter side ac network (with the nominal frequency of $f_{I}$ ), it will be modulated by the switching function of an inverter. Complicated harmonics are thus produced in the inverter side ac currents. This phenomenon can be depicted by the modulation equation in the following [8-11].

$$
\begin{aligned}
& i_{a c-i n v}(t)=i_{d c} \times \frac{2 \sqrt{3}}{\pi}\left\{A+\sum_{m=1}^{\infty}\left[B_{m}+C_{m}\right]\right\} \\
& A=\cos 2 \pi f_{I} t \\
& B_{m}=\frac{-1}{12 m-1} \cos 2 \pi(12 m-1) f_{I} t \\
& C_{m}=\frac{1}{12 m+1} \cos 2 \pi(12 m+1) f_{I} t
\end{aligned}
$$

Since the magnitude of a harmonic current induced would

\begin{tabular}{|c|c|c|c|c|}
\hline$N$ & \multicolumn{2}{|c|}{$50 \mathrm{~Hz} / 60 \mathrm{~Hz}$} & \multicolumn{2}{|c|}{$60 \mathrm{~Hz} / 50 \mathrm{~Hz}$} \\
\hline & (10a) with & (10a) with & (10a) with & (10a) with \\
\hline & "+" operation & “-” operation & “+” operation & “_” operation \\
\hline 1 & 50 & 50 & 60 & 40 \\
\hline 2 & 100 & 20 & 120 & 20 \\
\hline 3 & 150 & 30 & 180 & 80 \\
\hline 4 & 200 & 80 & 240 & 140 \\
\hline 5 & 250 & 130 & 300 & 200 \\
\hline \multirow[t]{3}{*}{6} & 300 & 180 & 360 & 260 \\
\hline & (10b) with & (10b) with & (10b) with & (10b) with \\
\hline & "+" operation & “-” operation & "+" operation & “-” operation \\
\hline 7 & - & 250 & - & 80 \\
\hline 8 & - & 200 & - & 20 \\
\hline 9 & - & 150 & - & 40 \\
\hline 10 & - & 100 & - & 0 \\
\hline \multirow[t]{3}{*}{11} & - & 50 & - & 60 \\
\hline & (10c) with & (10c) with & (10c) with & (10c) with \\
\hline & "+" operation & “-" operation & “+” operation & “_” operation \\
\hline 7 & - & - & - & 180 \\
\hline 8 & - & - & - & 120 \\
\hline 9 & - & 270 & - & 60 \\
\hline 10 & - & 220 & - & 0 \\
\hline 11 & - & 170 & - & 40 \\
\hline
\end{tabular}
decrease as the harmonic order increased, only the ones modulated by the term $A$ and the ones modulated by the terms $B_{1}$
Table 4. Frequencies of the rotor power disturbance $(\mathrm{Hz})$ for the fire-through faults in two types of HVDC link.

and $C_{1}$ are notable. For those notable harmonics, their frequencies can be expressed as the following.

$$
f_{\text {harm-inv }}=\left\{\begin{array}{l}
\left|N k f_{R} \pm f_{I}\right| \\
\left|N k f_{R} \pm 11 f_{I}\right| \\
\left|N k f_{R} \pm 13 f_{I}\right|
\end{array}\right.
$$

According to that, it is expectable that the non-characteristic harmonics will be generated. As an illustration, if $f_{R}=50, f_{I}=60$, and $N k=1$, a $10 \mathrm{~Hz}$ and a $110 \mathrm{~Hz}$ distortions will be produced in the inverter side ac currents. These two harmonics are significant because they are non-characteristic ones for a $60 \mathrm{~Hz}$ power system. In addition to these two harmonics, some high frequency harmonics will also be induced, however they will be filtered out by the ac filters.

\section{Modulation in Generator}

When the non-characteristic harmonics inject into a generator, a pulsation disturbance on the turbine generator rotor power will be induced. Since the reference frame transformation from stator to rotor is the same as a rectification process [16], the frequency of such a power disturbance can be derived as in the following by the modulation theorem, too.

$$
f_{\text {rotor }}= \begin{cases}|| N k f_{R} \pm f_{I}\left|-f_{I}\right| & (10 a) \\ || N k f_{R} \pm 11 f_{I}\left|-f_{I}\right| & (10 b) \\ || N k f_{R} \pm 13 f_{I}\left|-f_{I}\right| & (10 c)\end{cases}
$$

According to that, the rotor power disturbance frequencies can be obtained and tabulated in Table 4 for both the $50 \mathrm{~Hz} / 60 \mathrm{~Hz}$ and $60 \mathrm{~Hz} / 50 \mathrm{~Hz}$ links. The table is established just for $N k<12$ and $f_{\text {rotor }}<300 \mathrm{~Hz}$. It can be seen that both the sub- and 

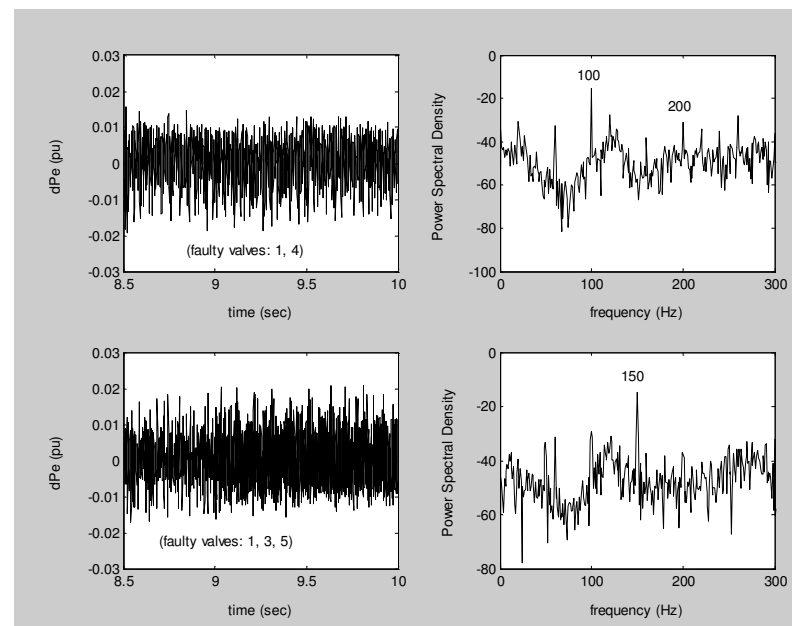

Fig. 7. Generator electric power errors for the two cases of fire-through fault.

super-synchronous disturbances might be induced. The most noteworthy is that the ones with integer multiple of the rectifier side system frequency were induced. That means the disturbances of rectifier side characteristic frequencies would transmit through the HVDC link to impact the inverter side turbine generators, which is a phenomenon not existing in a pure ac system.

Since the fire-through in a valve is usually hard to be detected and may exist for a long time, there would be a steady state excitation on the turbine generator, which provides a chance for an electromechanical resonance to build up. That will threaten the safety of a turbine generator.

\section{STEADY STATE SIMULATIONS}

In order to examine the possibility of inducing an electromechanical resonance by a fire-through fault happened in the rectifier valves, steady state simulations were made for the hvdc system studied. In the program, a thyristor is replaced by a diode to simulate a fire-through fault.

Two cases are studied. In the case 1, a fire-through fault is placed in valves 1 and 4 . It is like the case $b$ in Table 3. In the case 2 , a fire-through fault is placed in valves 1,3 and 5 . It is like the case $\mathrm{c}$ in Table 3 .

The steady state responses for the two cases are shown in Fig. 7 , including the time behavior and spectrum of the generator electric power error. It can be found that all of the harmonics predicted are present though so small. For the case 1, the power error primarily consists of the components with frequencies in integer multiple of $100 \mathrm{~Hz}$. As for the case 2 , it primarily consists of the ones with frequencies in integer multiples of $150 \mathrm{~Hz}$. Therefore, a steady state excitation in such frequencies will be imposed on the turbine mechanism. An electromechanical resonance may be gradually built up if there is a coincidence between the excitation frequency and the turbine natural frequency.

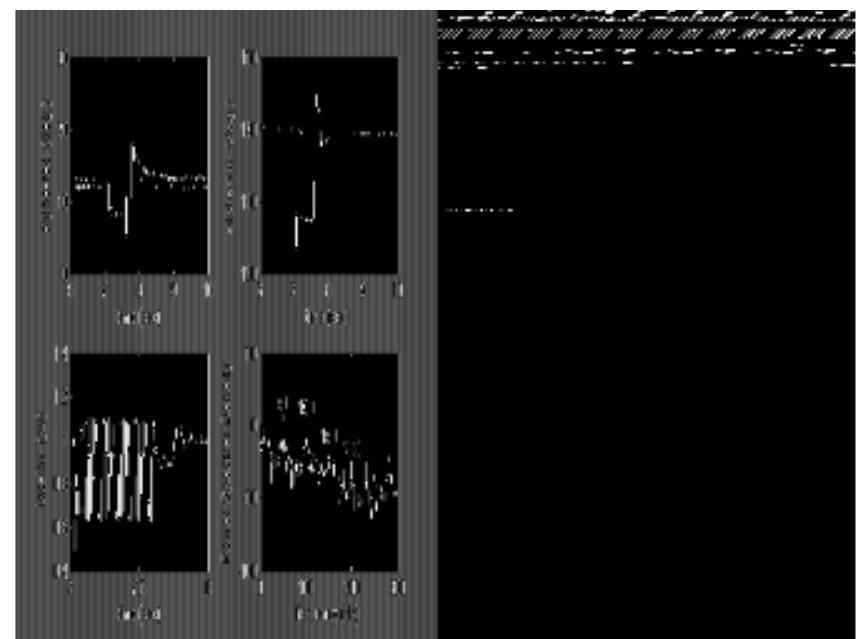

Fig. 8. Converter firing angles and de line current under the misfire fault.

\section{ANALYSIS OF A MISFIRE FAULT HAPPENED IN RECTIFIER VALVES}

Misfire is that a valve fails to take over conduction at the programmed instant although its voltage has the correct polarity [5]. For such a fault, it will also disturb the valve conduction sequence in a repetitive way. However, even a misfire fault occurred in a valve alone could induce relatively large transient disturbance to the HVDC system. So the impact arising from a misfire fault on a turbine generator is primarily in a manner of transient torque, which is different from the one arising from a fire-through fault. However, the disturbing frequency of transient rotor power could also be predicted by the modulation theorem [22]. For a single-valve-misfire fault, in addition to a stepping change in rotor power, there will be a rotor power disturbance in frequency of ||$f_{R} \pm f_{I}\left|-f_{I}\right|$. Since $f_{R}$ differs from $f_{I}$ for an asynchronous HVDC link, such a frequency is not a characteristic one. So, it is possible to invade the natural torsional modes of a turbine generator.

For the system studied, the induced frequency is $50 \mathrm{~Hz}$ for $\mathrm{k}=1$ according to the above. That just invades the blade modes of the turbine generator studied. So the torsional torque amplification effect will be very much significant in the blade sections.

\section{TRANSIENT SIMULATIONS}

To examine the torsional torque amplification effect induced by a misfire fault happened in the rectifier, a transient simulation is made. It is assumed that the firing pulses to the valve 6 of the rectifier unit are missing at $7.0 \mathrm{~s}$ and recovered after 30 cycles. This is achieved by using an ideal switch to block/pass the firing pulses in the program.

\section{Converter Responses}

In Fig. 8, it shows the firing angles for the rectifier and inverter units (alpha-rec and alpha-inv), as well as the dc line 


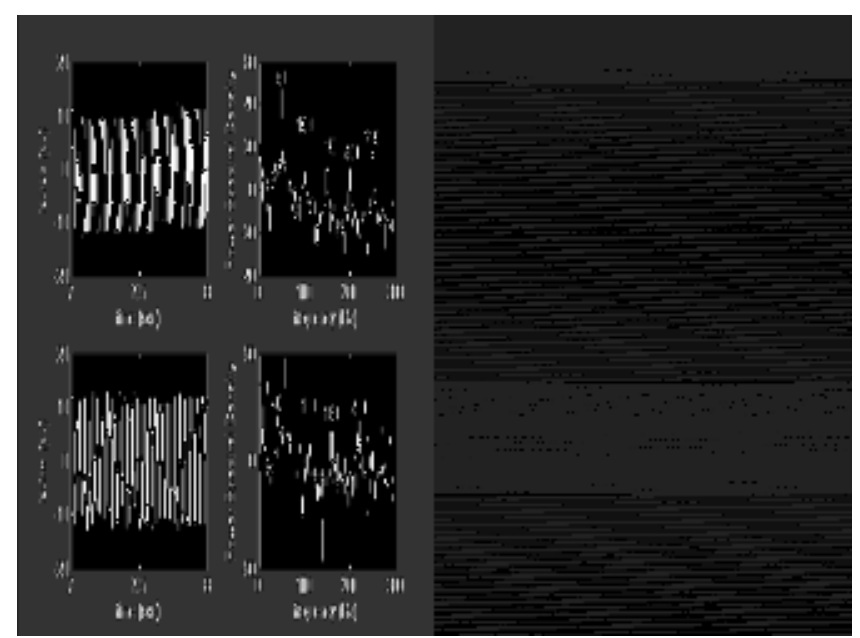

Fig. 9. Converter ac currents under the misfire fault.

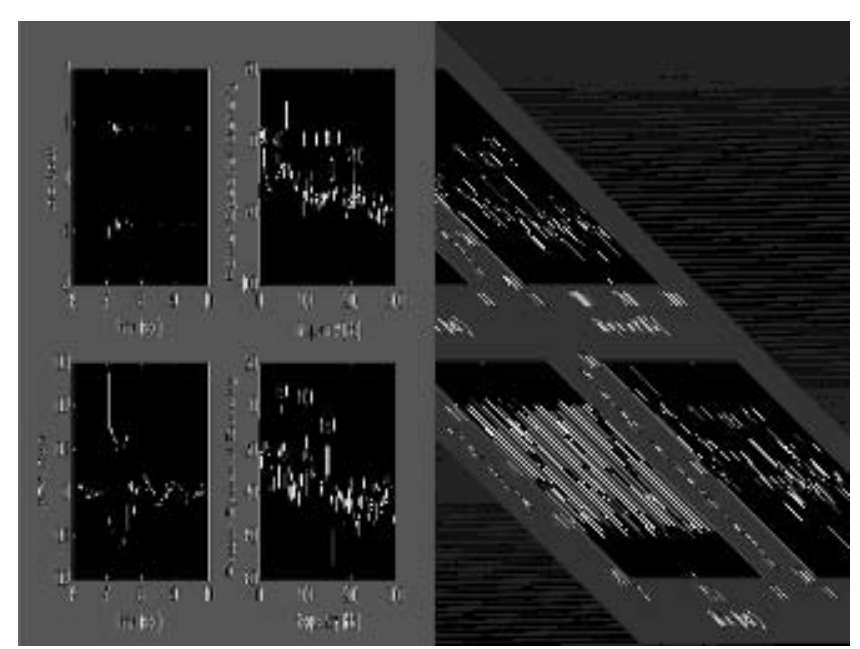

Fig. 10. Generator current and electric power error under the misfire fault.

current (idc-inv) and its spectrum. In steady state, the rectifier is operated in the current control mode (the firing angle is 13.5 degrees), and the inverter in the voltage control mode (the firing angle is 142 degrees). During fault, the rectifier changes between the current control mode and the alpha minimum limitation mode (the firing angle falls to 5 degrees and oscillates), and the inverter changes between the voltage control mode and the current control mode (the firing angle swinging between 125 and 140 degrees). The dc line current drastically drops at the fault application and then oscillates. It can be observed from the spectrum that the pulsation frequency includes $50 \mathrm{~Hz}, 100 \mathrm{~Hz}$, $150 \mathrm{~Hz}$, etc, just as predicted.

In Fig 9, both the phase-A currents of rectifier and inverter (ia-rec and ia-inv) are shown, and their spectrums are shown as well. It can be seen that, for the rectifier side ac current, the harmonic frequencies are in integer multiple of $50 \mathrm{~Hz}$. This result is the same as the one in [5]. For the inverter side ac current, the $10 \mathrm{~Hz}, 40 \mathrm{~Hz}, 110 \mathrm{~Hz}, 160 \mathrm{~Hz}, 210 \mathrm{~Hz}$, etc, harmonics can be found easily. That verifies the prediction by modulation theorem. One should note that these harmonics are non-characteristic ones for a $60 \mathrm{~Hz}$ system, which would not be

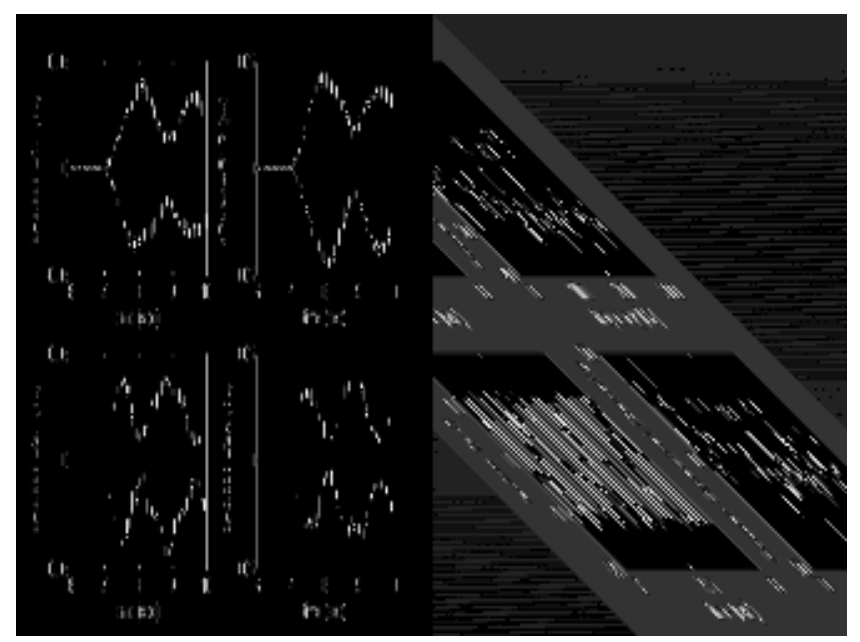

Fig. 11(a). Blade torsional powers under the misfire fault.

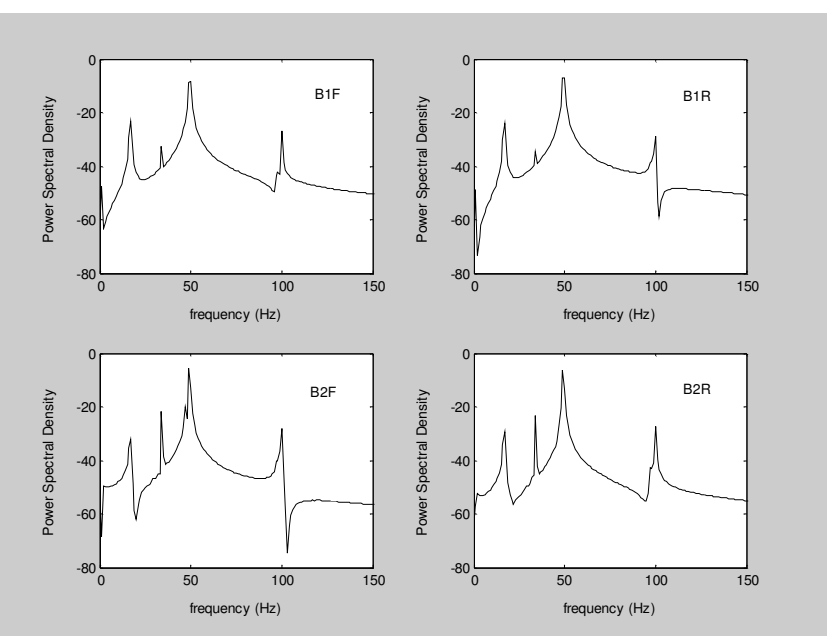

Fig. 11(b). Power spectral densities of the blade torsional powers.

induced in a pure ac system when subjecting to a line fault.

\section{Generator Responses}

In Fig. 10, the generator phase-A current (iga) and electric power error $(\mathrm{dPe})$ are shown, and their spectrums are shown as well. One can find that the non-characteristic harmonics really transmitted to the generator end. And it induces the sub- $(50 \mathrm{~Hz})$ and super-synchronous $(100 \mathrm{~Hz}$ and $150 \mathrm{~Hz})$ disturbances in generator electric power. The power disturbance induced is just about $0.4 \mathrm{pu}$ in peak-to-peak value, far smaller than the one induced by a line fault. However, it is significant because it contains the components in frequencies different from the ones arising from a local transmission line fault.

\section{Turbine Responses}

The transient responses of turbine blades are focused because their mode frequencies are neighboring to the excitation frequency. In Figs. 11(a) and 11(b), the torsional powers and their power spectral densities are shown respectively. It can be observed that the vibration frequencies (primary: about $50 \mathrm{~Hz}$, secondary: about $17 \mathrm{~Hz}, 34 \mathrm{~Hz}$ and $100 \mathrm{~Hz}$ ) are identical to the ones calculated by eigen-analysis. The maximum torsional 
powers in peak-to-peak value are $0.08 \mathrm{pu}, 0.09 \mathrm{pu}, 0.085 \mathrm{pu}$ and $0.07 \mathrm{pu}$, respectively, for the $\mathrm{B} 1 \mathrm{~F}, \mathrm{~B} 1 \mathrm{R}, \mathrm{B} 2 \mathrm{~F}$ and $\mathrm{B} 2 \mathrm{R}$ blades (note: the torsional power is equivalent to the torsional torque in $\mathrm{pu}$ value). These torsional powers are relatively large as comparing to their normally transmitting power of $0.0253 \mathrm{pu}$, yet are still smaller than the ones caused by a three-phase-to-ground fault. However, it is believed that if the mode frequencies were even closer to $50 \mathrm{~Hz}$, the torsional torques would be amplified to a level capable of damaging the blade structure.

It is noteworthy that the faulty rectifier is in more than $300 \mathrm{~km}$ away from the turbine generator. In general, even for a three-phase-to-ground fault could not impose such a serious impact on a generator in several hundreds of kilometer away for a pure ac system.

\section{VII.DISCUSSIONS ON FREQUENCY LIMITATIONS}

In a pure ac system, a Minimum Frequency Separation (MFS) is usually considered for disposing of the natural torsional modes of a turbine generator. Suppose that $\mathrm{f}$ is the system frequency, $\mathrm{N}$ is the rated rotor speed (in rpm) and $\mathrm{H}$ is the harmonic order, the MFS is usually defined as the following.

$$
M F S=5 \% \times \frac{N}{f} \times H
$$

However, this appears to be deficient for a generator in a HVDC system. According to the studies above, both the characteristic frequencies of sending and receiving ends should be considered for the MFS of a turbine generator in the inverter end, which is as the following.

$$
M F S=\left\{\begin{array}{l}
5 \% \times \frac{N}{f_{I}} \times H \\
5 \% \times \frac{N}{f_{R}} \times H
\end{array}\right.
$$

In addition, some non-characteristic frequency limitations should also be considered. The need for such a complex limitation is coming from that there is an interaction between the rectifier and the inverter.

\section{CONCLUSIONS}

The impact on a turbine generator arising from a fire-through fault is quite different from the one arising from a misfire fault in a HVDC system.

A fire-through fault happened in the rectifier valves could induce a small but sustained rotor power disturbance on an inverter side turbine generator. The steady state excitation makes it possible to build up an electromechanical resonance.

A misfire fault happened in the rectifier valves could induce a non-negligible transient rotor power disturbance on a turbine generator neighboring to the inverter station. The disturbing frequencies will be non-characteristic for the generator. The torsional torque amplification effect will be significant if any of the turbine natural modes were invaded.

To avoid the electromechanical resonance and/or the torsional torque amplification, even more complex frequency limitations are required for a turbine generator in a HVDC system.

\section{REFERENCES}

1. Arrilaga, J., "High voltage direct current transmission," IEE Power Engineering Series 6, Peter Peregrinus Ltd., 1983.

2. Breuer, G.-D., Luini, J.-F., and Young, C.-C., "Studies of large AC/DC systems on the digital computer," IEEE Transactions on Power Apparatus and Systems, Vol. 85, pp. 1107-1115 (1966).

3. Chyn, C., Wu, R.-C., and Tsao, T.-P., "Torsional fatigue of turbine-generator shafts owing to network faults," IEE Proceedings-Generation Transmission and Distribution, Vol. 143, No. 5, pp. 479-486 (1996).

4. Faried, S.-O., and Aboreshaid, S., "Stochastic evaluation of turbine-generator shaft torsional torques in a HVAC/DC Power System," IEEE Transactions on Power Systems, Vol. 17, No. 3, pp. 739-746 (2002).

5. Faried, S.-O., and El-Serafi, A.-M., "Effect of HVDC converter station faults on turbine-generator shaft torsional torques," IEEE Transactions on Power Systems, Vol. 12, No. 2, pp. 875-881 (1997).

6. Humer, M., and Kulig, S., "Measurement and assessment of torsion oscillations in turbogenerators by using a torque sensor and robust observer," IEEE 2003 29th Annual Conference of the IEEE Industrial Electronics Society, Vol. 2, pp. 1369-1377 (2003).

7. Harnefors, L., "Analysis of subsynchronous torsional interaction with power electronic converters," IEEE Transactions on Power Systems, Vol. 22, No. 1, pp. 305-313 (2007)

8. Hammons, T.-J., Tay, B.-W., and Kok, K.-L., "Power links with ireland -excitation of turbine-generator shaft torsional vibration by variable frequency currents superimposed on DC currents in asynchronous HVDC links," IEEE Transactions on Power Systems, Vol. 10, No. 3, pp. 1572-1579 (1995).

9. Hammons, T.-J., and Bremner, J.-J., "Torque in turbine-generator-exciter shafts due to DC currents in asynchronous HVDC links," Electric Machines and Power Systems, Vol. 25, pp. 87-105 (1997).

10. Hammons, T.-J., Lim, C.-K., Lim, T.-P., and Kacejko, P., "Proposed 4GW Russia-Germany link- impact of $1 \mathrm{GW}$ inverter station on torsional stressing of generators in Poland," IEEE Transactions on Power Systems, Vol. 13, No. 1, pp. 190-196 (1998).

11. Hammons, T.-J., and Mui, W.-G., "Turbine, generator, system modeling and impact of variable-frequency ripple currents on torsional stressing of generators in Poland and Sweden: Lithuania/Poland and Sweden/Poland HVDC links," IEEE Transactions on Energy Conversion, Vol. 15, No. 4, pp. 384-394 (2000).

12. Kim, C.-K., Yang, B.-M., Ahn, Y.-H., and Choi, J.-G., "Impact of generator of inverter station on torsional dynamics of HVDC system," IEEE 2002 28th Annual Conference of the Industrial Electronics Society, Vol. 1 , pp. 538-543 (2002)

13. Lin, C.-H., "Frequency limitations for disposing natural torsional modes of a large scale turbine generator in an asynchronous HVDC system," International Journal of Electrical Engineering, Vol. 14, No. 1, pp. 51-64 (2007).

14. Lin, C.-H., "The effects of a MOV surge arrester on blade vibrations of a large scale turbine unit," Electric Power Components and Systems, Vol. 31, No. 8, pp. 757-776 (2003)

15. Lin, C.-H., "Restricting turbine blade fatigue based on electromechanical-analogy circuit analysis," International Journal of Power and Energy Systems, Vol. 22, No. 3, pp. 150-158 (2002).

16. Lin, C.-H., Tsao, T.-P., and Tsai, W.-C., "Tuning the ratio of $\mathrm{K}_{\mathrm{GEN}-\mathrm{LP}} / \mathrm{H}_{\mathrm{GEN}}$ to suppress vibrations of turbine blades," International Journal of Electrical Power and Energy Systems, Vol. 22, pp. $435-445$ (2000).

17. Mortensen, K., Larsen, E.-V., and Piwko, R.-J., "Field test and analysis of torsional interactions between the Coal Creek turbine-generators and the CU HVDC system," IEEE Transactions on Power Apparatus and Systems, Vol. 100, No. 1, pp. 336-344 (1981).

18. Padiyar, K.-R., and Prabhu, N., "Design and performance evaluation of 
Subsynchronous Damping Controller with STATCOM," IEEE Transactions on Power Delivery, Vol. 21, No. 3, pp. 1398-1405 (2006).

19. Pillai, G.-N., Ghosh, A., and Joshi, A., "Torsional interaction studies on a power system compensated by SSSC and fixed capacitor," IEEE Transactions on Power Delivery, Vol. 18, No. 3, pp. 988-993 (2003).

20. Phadke, A.-G., and Harlow, J.-H., "Generation of abnormal harmonics in high voltage AC-DC power systems," IEEE Transactions on Power
Apparatus and Systems, Vol. 87, pp. 873-883 (1968).

21. Shi, W., and Iravani, M.-R., "Effect of HVDC line faults on transient torsional torques of turbine-generator shafts," IEEE Transactions on Power Systems, Vol. 9, No. 3, pp. 1457-1464 (1994).

22. Yacamini, R., "How HVDC schemes can excite torsional oscillations in turbo-alternator shafts," IEE Proceedings-Generation Transmission and Distribution, Vol. 133, No. 6, pp. 301-307 (1986). 